\title{
Scheme Developing (Alternative) Promotion Designing for Visual Communication Design
}

\author{
Mochamad Ficky Aulia ${ }^{1},{ }^{*}$ Agus Darmawan ${ }^{2}$, Tulus Rega Wahyuni ${ }^{3}$, Elida \\ Christine $^{4}$ \\ ${ }^{1}$ Nusa Putra University, Sukabumi, Indonesia \\ ${ }^{2}$ Nusa Putra University, Sukabumi, Indonesia \\ ${ }^{3}$ Nusa Putra University, Sukabumi, Indonesia \\ ${ }^{4}$ Nusa Putra University, Sukabumi, Indonesia \\ ${ }^{*}$ Corresponding author. E-mail: agusdarmawandkv@nusaputra.ac.id
}

\begin{abstract}
As we all know, Visual Communication Design (VCD) major is available in many institutions in Indonesia as of late. Students are expected to participate and compete in industries and society. Rivalries are often found in the working environment and are not exclusive to VCD graduates. Designers that have roots in other majors are not rare to find. This is an indication for our graduates to find a position that delves deeper into media creation with a methodical approach if we take advertising as an example, where the review and understanding of products and services are essential to achieve needed context, which is one of the main topics of Visual Communication Design. This planning is an alternative guide to the various scale of planning processes. To be an alternative is an ideal option in certain areas - for example, industry. What differentiates this from designers is that designers translate/visualize client briefing results. Instead, this planning serves as a starting point and guides participants in reviewing the product. The basis of this structure Is a mix of concepts from Laswell, Albert Humphrey, and Buzan adapted in the advertising industry. Therefore, the advertising planning structure will lead students to develop innovative/interesting concepts and effective media considering various related issues. The urgency lies in the lecture process, which is the basis of research to educate planning structure until this journal is formed as another introduction that includes an evaluation of what is presented in lectures.
\end{abstract}

Keywords: Visual Communication Design, Advertising, Promotion, Scheme Design.

\section{INTRODUCTION}

Visual Communication Design is a scientific phenomenon that came too late in the form of exclusive education in Indonesia [1]. Although historically, traces of DKV's can be seen both in the media of spirituality (religiously related) during the royal era, or the printing press introduced by the Dutch in the 17th century, or even through the intellect of the Maestro Raden Saleh when he was an assessor of letters, words, and sentences. for the Bible translated into Javanese by Gottlob Brückner (1829).

Through the history journey, VCD has become even more popular. The factor is that the increasingly widespread media landscape supported by technical equipment has opened up the emergence of creative activities. It is proven that DKV can penetrate all lines. In a sense, someone outside or who does not study design science specifically can be said to be 'can' do design activities. This paradigm, which is a natural way of working in the field, has made the value of science itself blurry about a boundary. In other words, either directly or indirectly, there has been a reduction in educational values during learning, especially in the methodological part of the study. The popularity of design in a definition is returned to an effort made by Bekraf about "value creation from problem-solving." However, this definition is not sufficiently coherent 
with the knowledge gained in the world of lectures and what is happening in the field at the industrial level. Design graduates are not as exclusive as problem solvers.

Most graduates in the world of work in the field only serve clients' wishes, and especially the media formation process always experiences too deep intervention like a patient by himself offering a drug solution or choosing a specific injection site to a specialist. That is, the needs of the industry are undoubtedly different from what conditions have become food for students in college. This problem continues in seminars on campuses that are only limited to motivation in the form of a portfolio with a thick "problem solver" jargon without any methodological reference.

The industrial world wants something concrete (and often faster) in serving the needs of its company. So, this is the entry point for the intended definition effort, where the designer acts as a problem solver by translating a company brief through the requested media. It does not matter if it becomes a solution to a problem in an industrial context. It is just that in the world of education itself, it is more important to prioritize the journey of the media formation process based on a way of thinking and stringing problems from the initial stage. Therefore, this promotion design scheme is an alternative method in doing these things, where the briefing process is part of it.

\section{RESEARCH METHODS}

This design scheme is formed through the research method included in a DKV teaching. Especially for the DKV 1 studio course, which includes the world of advertising. Students are expected to be able to project a promotional need for products/services belonging to relatives or family or a medium-scale company (even large if possible), as a form of simulation or even into an actual project. This research is to find out the effectiveness of a proposed scheme. In addition, this alternative design scheme is also used for several courses that are still in contact with methods - such as research methodologies, design methodologies, or, popularly known as Design Thinking. The type of method used in this projection is a dual method (quantitative and qualitative) to find out the achievements of the offered scheme and find new problems that can continue to be evaluated later.

The research process goes hand in hand with teaching cycles in odd semesters, especially courses that contain advertising material, which has effectively been going on for 2 years. However, several batches of students have taken face-to-face lectures in other subjects that require a similar method.

\subsection{Data Collecting Method}

These data were obtained through a questionnaire distributed to one hundred students and a descriptive understanding of the basis for qualitative methods by reading from students' results (Final Project level) who did not use the design scheme. As a note, for the last case, the author will not describe the factors causing it for one reason or another that is complex.

Meanwhile, the research study area is the campus of Nusa Putra University, Sukabumi and STMIKAMIK Bandung. Where is the role of the author as a supervisor for the DKV 1 studio course at UNSP and Research Methodology at STMIK-AMIK and also fellow researchers as supervisors of the Research Methodology course at UNSP.

\subsection{Data Analysis}

The pooling on the students in two places shows a percentage of $40 \%$ who come from students undergoing lectures in semester 3, and $33 \%$ are undergoing in semester 5. Problems are opened through the stage of specialization in Visual Communication Design as the chosen scientific discipline. The highest reason (66\%) is in the interest of those who like DKVan activities. Meanwhile, $41 \%$ of those just want to learn DKV. The rest is thinking of himself trapped and entering the wrong majors. However, this cannot be used as an essential reference because not all students from all generations have filled out this questionnaire.

Then the answers from respondents who stated that they knew that 'design is an effort to create value from problem-solving total 93. Moreover, they also understood which subjects were at least related to the problems that must be solved in the world of design. Elaborating on the answer further is the limitation of how the solution emerges. Students understand the need for research but are scattered in collecting data material and bringing up ideas packaged into concepts as solutions accompanied by media executions. This case is mainly found in students who have just started studying at level 2. However, students at level 3 who have progressed from task variants that are increasingly leading to concepts have been able to serve problems through this method. 
However, of course, it cannot be separated from the role of the teachers through the guidance process regularly, as by reviewing the weight of the problems in the context of each student.

Then the next stage is about the effectiveness of a taught scheme, referring to a positive trend with the results of the answers of 94 respondents. What should be noted is that this method depends on the focus of the study/design. The factors are varied; from the scheme itself, which demands basic things through research, online teaching that is often disconnected, various levels of reasoning, the prosecution of a more practical scheme, attendance in class, and consistency in doing assignments. In a description of a more specific cluster, there is still a lack of understanding in adapting the design scheme. This is also positively welcomed as self-criticism and evaluation for the supervisors to continue to improve these things. One of them is by way of descriptions in this journal, outside the consultation facilities in the learning process both inside and outside the classroom.

For students who do not use design schemes, it can be identified that there is no regular basis for a design, both in terms of data, research methods, related problem theory to application. Then there is no weighty value in a design application. Finally, the design is always interpreted as a form of shortcut that exists and only displays the external form without paying attention to the crucial, elementary things.

\subsection{Theory Analysis}

Visual communication is a bridge from a wedge that becomes the focus of every DKV scientific post, such as the role of DKV working in information, identity, education, entertainment, and persuasion (product/ candidate/ social campaigns) [2]. Continuing from before, that design does not appear as a single form of expression but in an applicative position, where its status becomes active when it acts as a need to satisfy a larger scale. Exactly as what will be described next in a promotional design projection.

Promotion is one type in the Product Oriented Campaigns position in a campaign classification where persuasion focuses on the status of selling products/services to seek profit [3]. An understanding of promotion as a form of marketing communication ensures that these products/services can be accepted, purchased, and become loyal customers [4]. Then we find out about feasibility studies in a design, especially in the promotion.

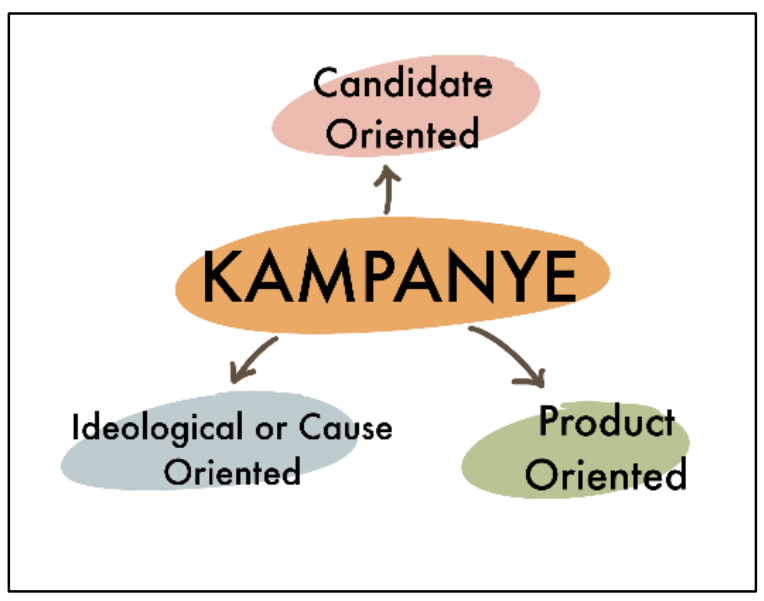

Figure 1. Campaign model

This always starts with a problem that must be solved through a solution. However, the problem does not stop at a single request or a problem itself but relies on how we can get a practical solution until it ends in the phrase to answer 'what is the solution?'. This will be the breakdown of solutions in the form of a comprehensive alternative method for students. Beyond the ability of someone who can carry out "professional judgment" on the observation of a project, media packaging, and at the implementation stage and exclusive presentation of the work, it often ends up confusingly causing various questions that have not been completed. The author will try to offer an actual methodical idea. It is an adaptive result of a combination of various existing methods. Moreover, this form of scheme has gone through research, trial, and evaluation to measure the level of success, where the emergence of value will be achieved through research studies for project actors.

In its development, this method has many names in the Visual Communication Design tradition, starting from Mind Maps, Fractals, Brainstorming, Mind Boards, Mood Boards, Affinity Mapping, Mind Trees, and the like. They are usually arranged in a string in the branches of points, as the author did by breaking down several categories based on the portion of work. This can be a logical reason to parse data, thoughts, and ideas that will be prone to escape if too scattered in the head.

The definition of a Mind map by Michael Michalko is the development of creativity in formulating ideas contained in his eccentric book Mind Map. It seems relevant enough to be a foothold in this design scheme., He mentions that Mind Maps are an alternative to whole-brain thinking, too linear 
thinking. The Mind Map reaches out in all directions and captures thoughts from all angles. Furthermore, Michalko explains the function of the Mind Map itself in Cracking Creativity, namely; activates the whole brain, clears the mind from mental clutter, allows us to focus on a subject, helps show the relationship between separate pieces of information, gives a clear picture of the whole and in detail, allows us to group concepts, and helps us compare them [5]. For Buzan himself, this is to save time in solving problems by preparing a plan that directs us to act more creatively, pay attention, focus, and be more efficient. Applying the points is not only with traditional text but can be very revealing with visual placements, such as photos or icons as the intended symbol.

This becomes an interesting idea for how the archiving of information and ideas can be neatly arranged (by grouping) and the flexibility of opening oneself (ideas) to any possibility, both theoretically and naturally. Achieving a design goal takes much material, data, theory, and ideas. Therefore, a minor ingredient that can be dissolved into it is the popular communication theory (later) by Harold Laswell with his $5 \mathrm{~W} 1 \mathrm{H}$. The author will present a sequential breakdown of the scheme that has been designed. However, not at the detailed level of technical presentation of what is described by Buzan's method, such as in the application of lines and colors. However, the method's usefulness is applied to the idea formation cluster. This design scheme is the basics of the research process, where the scientific taxonomy can be connected with several relevant courses in the Visual Communication Design study program.

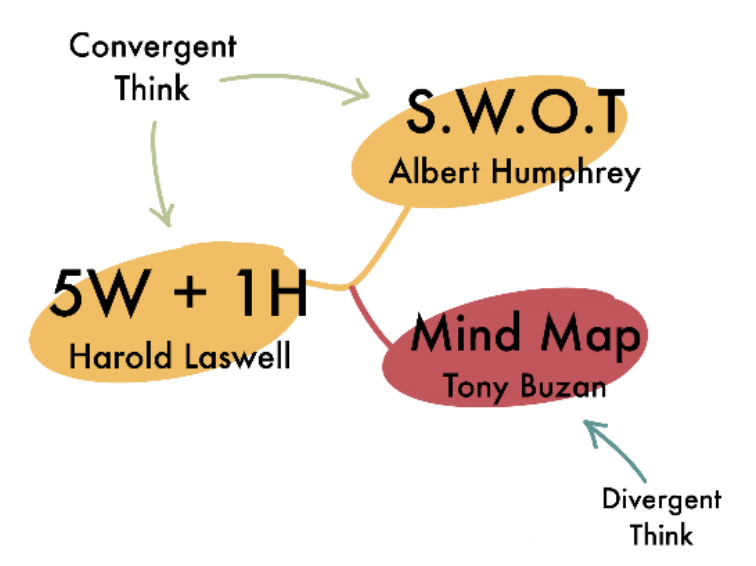

Figure 2. Basic Scheme

Specifically, the function of a design scheme is to guide entry into a convergent and divergent framework of thought. Convergent thinking is an analytical way of thinking. It is rigid because it is related to data. So that students are not too far away in determining the media in reading data [6]. Then Divergent itself is a way of creative thinking, how ideas can be built through the possibilities of interrelated meanings [7]. There is no higher degree between the two. Because both are mutually needed between each other, if we focus on convergent thinking only, the work produced will be flat and dull. This is because there is no meaning in the empathy process approach. Moreover, if we overthink Divergent, of course, we will find things that are unique and very creative. However, the weakness lies in not being able to read detailed data, which is how the company's needs began.

It should be noted that software has emerged to practically facilitate this kind of mapping, such as; $\mathrm{X}$ Mind, ClickUp, MindMeister, Milanote, Microsoft Visio, MindGenius, Miro, SmartDraw Lucidchart, Coggle, and others. Even students can quickly assemble data and ideas, as long as they go through a paid procedural. Moreover, this software can connect directly to a series of web addresses or display the required media. However, this software is only a template. In other words, we still have to pour the contents into tabular branches. On the other hand, as presentation material, not all software can facilitate the display of designs to realize the visual theme of one focused study. However, it all comes back to the selection of cultivation media because it is all used as an alternative way to map what has been obtained and what we will do later.

\subsubsection{Cluster I - Planning Map}

This is the first step as a projection planning to get directed information and work schedule in a design projection.

\section{- Product/Service Determining and Problem} Potential

The emergence of problems in the promotion system always starts from studying related products/services based on primary, secondary, and tertiary needs. Especially when it comes to more specific issues, what it will probably find out is to answer whether product $\mathrm{A}$ is a new release under the roof of a newly founded company? Alternatively, expanding a business from an existing brand introduces a new type of product? or other problems related to its products and institutions. According to this situation, we will know the beginning of various potential problems. 


\section{- Research Methode Determining and Research Instrument}

The choice of multiple methods can be suggested to get more comprehensive data in forming the foundation of marketing strategy through advertising. We can use the method as the method that has been presented in a standard way, both through qualitative and quantitative methods. The example in the qualitative method itself in the interview instrument helps determine the ins and outs of the potential of the quality of the product/service and the potential and orientation of the company, which will then be connected with the SWOT analysis. Alternatively, we can read the psychographic characteristics of consumers with descriptive understanding through existing media. While in the quantitative method, we can look for the audience's characteristics, which include geographic and demographic criteria. On the other hand, quantitative methods can also read aspects of product/service potential (which may have existed before) from the audience's point of view.

\section{- Data Searching for the Client \& Audiences}

This is a practical step in extending the previously defined method. Usually, the search for audience data can start when you have received information (about the plan or applied) for distribution. At least this will lead to a space where our movement will lead. The data acquisition results can be read in the data/data $5 \mathrm{~W} 1 \mathrm{H}$ mind map session. On the other hand, this stage is also the limit of our work on a project. This is so that the work process can later work well because the alignment has been arranged. Unless the project is aimed at us, there needs to be more clarity on that.

\section{- Program Scheduling.}

Deadline is crucial in the projected timeline. This timeline does not matter if placed at the beginning of the research determination. It is just that it is usually determined after the brief has been discussed. So, the preparation of the work agenda will at least lead to an efficient and effective work system.

The steps above will lead to a new cluster analyzing the data from the results obtained. We will think about how to read data from the material that has been collected. The author calls it a data mind map/5W $1 \mathrm{H}$ data that contains a data formulation strategy, where the contents can position points in each capacity as research material, which will later be helpful as a processing component of the idea crystallization process because of all that, grouping the scattered data would be ideal as a second strategy.

\subsubsection{Cluster II - 5W+1H (Data)}

This is a standard method in communication theory. Where Harold Dwight Lasswell managed to formulate it with "Who Says What in Which Channel to Whom with What Effect?" (Early communication theory, 1948). Although when we look further, this is an extension of the mind of the English writer, Rudyard Kipling. The difference between the two is that Rudyard Kipling is designed as a writing method in determining the storyline in his literary works. At the same time, Laswell himself cultivates it as a communication model. What is essential for the author himself lies in the effort to place $5 \mathrm{~W} 1 \mathrm{H}$ in the data parsing class. This classification is also a benchmark and the development of media foundations in building communication to the audience through data. The material obtained uses a selected research method and related literature theory as a scalpel in understanding the related context, such as; DKV science, product management, to psychology in understanding the intended audience's criteria.

\section{1) What}

At this point, the creator can place the starting stone that has been obtained through research studies. From the essential things, such as the name of a product/brand type of business, vision-mission, product/business variants, materials used, production costs in a product, product position today, and the like related to product characteristics.

- SWOT Analysis. Before entering another ' $\mathrm{W}$ ' point, the author tries to insert an analytical method popularized by a Harvard professor, Albert Humphrey, with the acronym SWOT's theory. An alternative application of this analysis is inserted to see a more profound potential of a product value or the company itself. As we know, we are directed to the complexity of the payload, such as:

- Strength. Which can parse the various advantages or strengths of the content of a product/company. One of them can be 
used to implement good HR points, hygienic processes, low prices, or the company's only specialization in a particular field. This point is helpful in the later brainstorming stage, where we can break down the derivatives of each keyword in the formation of associated ideas. At least (if) necessary to avoid explicit exploitation of product components.

- Weakness. It is like a joke when you have to read and parse the problems of the product/company that we work on. We can find various problems in the company's kitchen, such as the lack of human resources, low distribution, or the minimum interest of the consumer in the product itself. However, the existence of these weaknesses triggers us to be able to overcome these problems systematically.

- Opportunities. Then we come to a stage where we will read potential strengths and weaknesses as opportunities that will be resolved through other strategies, reviewing the things connected to profit from them. For example, we can see an opportunity for a social phenomenon such as the increasingly massive use of gadgets abroad and strategic distribution. This kind of thing can be used as a reference as an opportunity.

- Threats. In the last stage, we will find problems in the form of threats or read as challenges. Competitors are familiar with the corporate world. At least we need to know both general and specific discourses of what competitors have positioned for consumers. Another thing, this point can also be read as a form of anticipatory response to unspoken possibilities. It can be related to the phenomenon of media and technology devices or even natural disasters.

2) Where. Then returned to the other $W$ position as a series of $5 \mathrm{~W} 1 \mathrm{H}$. This point can read geographical problems or the company's existence in the natural and virtual world, including region-bound distribution systems, in some instances, "where" can also be a media limitation when channeled. Even by reading the regional potential, the promotion strategy can weigh the effectiveness of the media through a cultural approach. For example, in the case of Djarum Chocolate and Djarum 76 cigarettes, the distribution has been in different regions even though they are under the same company roof. So, the intensity of the media promotion is suppressed in each region. For this reason, promotional media may consider regional matters.

3) When. The portion in this point has a relative nature. We can review the company's characteristics in handling its products from the start. Mainly as an extension of the "What" point. The only thing that binds the relativity of this point in time. Where can we put historical points, or the phenomenon of a public need sticking out (such as the case of masks during covid), or simply the activity of a shop in serving its consumers, such as the opening and closing hours of a cafe.

4) Who. A product is designed based on a company idea by considering a community need. The following way of working is to attract the broader community into a group of consumers. For this reason, consumer analysis is a pillar that cannot be removed as in other DKV ways of carrying out its functionality. The nature of the promotion itself is to get as many consumers as possible. However, at the level of progress in the field, things are achieved gradually with various considerations, namely the priority of the target market, to provide a decent profit from a product launch. Moreover, the purchasing power of a group of consumers is often considered, where we can see the potential for product distribution. The central review can be done by observing the segment criteria based on the product. Here we can read the segment as a general user in product consumption. Such segments from Playboy magazine are not suitable for consumption by a certain age (children). This is an explicit explanation so that the launched product can be classified appropriately. Things like that also do not rule out the possibility of revealing data through geographical, demographic, and psychographic studies. This segmenting mapping serves as a stepping stone to more angular consumer 
research. The problem of segmenting is at the level of product reality. Where there is a distance that is not possible to be consumed by a particular group. Therefore, there is a need for a more precise category breakdown in determining the market (related to marketing). Targeting is an outstanding effort in determining this group of markets. With this, we can parse the criteria related to; geographical - as a regional reference which also allows opening opportunities in distribution. The second is Demographic - a criterion specific to the market's characteristics, which includes age, gender, type of occupation, and economic class. The third is psychographic - this point triggers many things that can be explicitly described in determining psychographic points. Because this is related to the patterns of habits of the target market, such as the scope of activities, hobbies, lifestyles, even trivial things, its function is to see opportunities where these media can be channeled effectively, especially if they can relate a criterion to a problem at the "Why" point. As an additional note, to see the tendency of the characteristics of the three points above, apart from direct observation and social media. Some websites serve this, one of which is the I know you.app., but not all of them can access this website.

5) Why. This point contains how important this product is in an advertising projection. A promotion then becomes part of a company's need that offers a product/service. In addition, "Why" can read the reasons associated with a momentum of what is happening in many phenomena. Like the phenomenon of agate, Louhan fish, or folding bicycles. In other words, the term "seasonal" can be used as an opportunity for a product positioning, where its presence can trigger a consumerism culture that is born through consumer needs for products. However, it does not become an entirely "seasonal" phenomenon that disappears quickly like "Monkey Business." There are several studies of human psychographics connected with media wrapped in technology where technological advances force us to remain active in using them, maybe even being able to shift tools that are considered ancient. As in the case of using gadgets and the presence of internet facilities, it seems to be moving in a more established direction because it is connected to needs that are used mainly. In primary form. So, these patterns can be used as an opportunity in planning the application of media in one of the advertising needs.

6) How. This point attempts to find a solution, with manifestations connected to the next cluster - brainstorming. Some points can be filled in outline, such as how we plan the steps to enter the promotion problem, both technically and in terms of systems and even capital, because it will all lead to a production reference that may involve a team with a portion of work later. Although not at the point of explaining specifically about budgeting, a little talk about capital is not a problem. Mainly media exploration is usually limited by budget matters. The size of the capital can determine the quality and achievements of the media. Plus, if the product is included in the category that just appeared. The relative budget, generally 5$7 \%$ of the total production, is a significant consideration in media execution. For this reason, creative strategies are needed to apply ideal and practical concepts. The essence of 'How' is how we read that the client's wishes can be met with the available standards so that the expectations of the media can be measured at a close distance before the ideas are finally conceived.

\subsubsection{Cluster III - Brainstorming}

Opening potential space, recognizing the brain, in a class, Brainstorming or commonly called Mind Mapping by Tony Buzan, is a method whose function is to crystallize ideas that arise in the minds of creators to rationalize abstract ideas into a series of keywords so that they lead to a concept later. Brainstorming also combines the idea with data and reinforces theories as a formulation.

Theories are not present as mere sweeteners, but they contribute as a determinant of the feasibility of media applications. So later, it is expected to be able to become something intact in attracting messages and impressions to the audience through the media. In the context of DKV, media supported by theoretical construction will not be in vain, especially if we study further in an increasingly established history and development that the practical world of DKV science is intervened by theory and experiment on a relative 
scale. For example, we can examine the promotion area using AIDA theory (Attention, Interest, Desire, Action) or look at the possibilities through Jean Baudrillard's perspective on Simulacra (Hyperreality). Especially if we also understand the study of marketing management or even other sciences that are considered as slices of a product category and its working system. So, this door will open creative opportunities to enter a stage of the concept maturation process.

The brainstorming process can be started with the idea that comes from the product's quality, for example, by observing the effect as an impressionbuilding stimulus. From one or more keywords, multiply through the proximity of corresponding values gradually until it is considered complete. The point content of this can be freely provided as long as it departs from the root of the initial keyword. The approach can be through causal elements or elements related to one another. With this, abstract ideas are poured out in the form of sequenced keywords. The results of these keywords will not only become pillars that are connected with a concept of media formation, slogans, and visual displays. They are also helpful as a reference for concept choices. The possibilities are so flexible that they reach the processing limits of related words or meanings. Because the arrangement is similar to that of a puzzle game, the human brain always enjoys relating things, where exploration produces rich ideas.

The concept is a series of ideas constructed in a creative area due to the internalization of the mind. Where we can work in the Divergent, think space: the thought process is looking for ideas - looking for new ideas. Moreover, Convergent Thinking: the process of critical thinking in analyzing problems to come up with creative solutions and choose a decision as a solution. Both models are open to each other to reinforce each other to get effective results. As in the case of promotion, which is no longer accessible, because in the process, it is necessary to consider ideas related to product data, audience data (segmenting \& targeting), theory, client wishes (in some instances), to budgeting.

Another thing that the author needs to explain in a note is that creativity itself does not have a definite measurement value. The weight of the load depends on the interpreter, and it is a blur of the quality of the adjective itself. However, in truth, projections always require creativity, where the adjective can be transformed into a verb needed in the DKV world. For this reason, it is necessary to have courses that stimulate the development of ideas.

\subsubsection{Cluster IV-Concept and Media Strategy}

The crystallization process leads to a media decision, which has the potential to serve the needs. Which media is selected will require a strategy. Meanwhile, there will be a sorting back where the media are separated into leading media and supporting media. However, the same technique can be used in completing the data description, as long as it is still connected to a concept carried out.

This cluster serves as a guide to enter into a different creative area. Where we mix philosophy, implying meaning in a visual package, which essentially mixes ideas into a concept. It will all meet in one outcome point and a solution, requirement, and theory.

In an advertising case, it is often embellished by imaging elements whose function is positioning. Positioning is the company's bidding effort to occupy a different position, and that value is placed in the minds of target consumers [8]. In this way, it is a way of placing oneself (company/product) in a space (which is created) amid competition, or in other words, positioning oneself as a specialization in a specific category. The closest media positioning is the slogan, where the company can go directly to the point it wants to form in a consumer's memory. A deeper approach can be strengthened by the sound element in which the slogan resides. The blending of slogans into a successful jingle can make the audience remember it faster, even if it is presented later by the printed media after going through the media through the helpful feature.

In terms of creative business foresight, other positioning media can also play an icon. Icons can be selected using the services of a public figure. We can see this method in one of Shopee's ways to promote Black Pink services or even Tukul in COD socialization. This is to gain an impression of both lifestyle and socialization through emotional closeness between the audience and the product. The level of bigotry can play in the field of one's mind, which stems from a sense of belonging or wanting to resemble, where the Simulacra - Baudrillard theory becomes relevant in this position. One will transcend the apparent reality by presenting a new reality through the mind.

\subsection{Media Concept}

This is the part where ideas have been converted into concepts that connect values in one media package. These values can vary. They can come from a history, production process, functional value, the effect of a product (in the form of an impression), a 
coveted icon, or become legitimate when we 'drop' a competitor's product metaphorically. This concept is a form of extraction from a keyword carried in a brainstorming process, which means that many other alternatives can be used as a reference in case of ineffectiveness because the ineffectiveness is not only in the placement of the media or the audience's characteristics but often occurs in the company's capital problems, which will not even materialize the media.

The media concept attempts to answer what media are effective as problem-solving in advertising [9]. Outwardly, we can choose the media that are considered effective in conveying a message with the categories of ATL, BTL, and TTL media channels (which are explained below). Alternatively, it just stops when sorting and selecting media based on the location of its application, namely indoor or outdoor media - or based on the system - namely electronic and print media. However, in bringing the concept closer to a goal, we can trick it into particular and chain domains where the space for media exploration can be directly adjacent to the audience, especially if there is an interaction by taking advantage of the opportunity of the moment, the media or even the use of materials. For example, in the case of moments, an Ambient Media is a coffee product installed near the bus stop in autumn. Through the mini digital board, the media only displays a cup of coffee that gradually releases steam. Although visually it is only two-dimensional, the sensation of warmth caused can be felt by the public transport watchers.

\subsection{1. $5 W+2 H$ (Media)}

There are many ways to apply a concept, which can also apply to supporting media. Therefore, to tidy up these concepts' arrangement, the author again offers a repetition of Harold Laswell's communication strategy. However, this time it was arranged in a media framework. Like a brochure that contains a barcode to display further/chain information on a web page or social media.

1) What. At this point, we can place the media that has been decided conceptually, both around the main and supporting media, from what media we want to design.

2) Where. Here are the points where we will put the media as needed. We can pull this into specific areas described in the 'moment' above. Alternatively, if in the case of TVC, we will know on which channel the target company is watching television shows or specific programs. Lamborghini advertisements will not place advertisements on a regional TV channel in Indonesia. Alternatively, vice versa, the promotion of dangdut koplo songs is not ideal if it appears on the BBC channel. However, another problem is when the fate of the media always boils down to social media, as is often encountered in lecture assignments. It becomes a ban because not a few activities have led to digital media. However, we need to review how big the company's projection is to serve its products. Of course, this cannot be beaten evenly in applying media with various scales. So, there should be a review in the project area to determine the effective media to be placed 'where.'

3) When. This time element point is bound by its space and has been explained above. This refers to reading in temporal probabilities by reading the audience's characteristics (demographic-psychographic). Again, in an explicit example, we can put advertisements for sexual products above family hours, put household needs in the morning, and place advertisements for ulcer drugs at dawn. Awareness in reading this opportunity should be carefully read to achieve media effectiveness.

4) Who. The audience is the source of all needs in product formation, distribution, and related advertising media. Its role in determining the media is through emphasizing a more specific audience by reviewing its criteria which may also be connected to a particular moment which means that its readability also considers space and time. The data that has been achieved at the $5 \mathrm{~W} 1 \mathrm{H}$ data point is the basis for moving forward at this stage. Some problems do not rule out taking existing samples. However, apart from stabilizing the position in customers' eyes, at least this opens another opportunity for other mission achievements, namely to reach new target markets with a new understanding context. On the other hand, problems with different needs, where the case of a concept that requires a figure in it, can also put it on this subpoint. A public figure who is considered appropriate in representing the image of a company or product can make it easier for the audience to absorb that impression. The shape 
is relative, it does not always have to have a charming face, but with a specific context, anyone can be presented according to the portion. The primary consideration is when at the scene level in a video ad being worked on seriously. So, good acting adds value to the interest of consumers. Apart from that, both ambassadors/ambassadors/endorsement actors can now enter specific spaces such as their social media accounts, which instantly wears off the requirements to be a model with good acting.

5) Why. This point contains reasons to answer how creators define media through the continuity of the problem and reading the previous points. Moreover, have the right reasons in the media design steps.

6) How 1 (How to do). This is a further step, how the selected media is applied. Like how and where the media is distributed. A TVC needs a channel for broadcasting, so at least information is needed as an introduction to finding out a series of media needs, including the area of broadcast costs in it. This, of course, also applies to other media.

7) How 2 (How Much). This point can be placed anywhere, usually depending on a brief where the capital is an alternative reference informing the media. The whole process in the formation of media always costs money. We can describe these things in as much detail as possible, from research costs, production teams, operational costs, production costs: talent, property, equipment rental, space rental, application costs, etc. However, the size of the cost depends on the projection and considering the company's scale.

\subsubsection{Media Strategy}

This step is a sequence of how the media can be distributed. A media classification is generally divided into Above the Line (ATL): top-line media with a vast spread potential but a time/duration limit. Such as TVC, Radio, Billboard, Magazine and Newspaper advertisements, and so on, which have the characteristic of paying to advertise agencies for broadcast, and there is no direct communication between the audience and the company/product. Below the Line (BTL) itself is a bottom-line media, where this media does not work through advertising agencies because the way this media works is through direct audience experience. Such as in auction events, product launching, sponsorships, SPG/SPB, or print \& electronic media (outside ATL) connected with the above activity, such as posters, banners, skyscrapers, flyers, catalogs, and the like that need context. Another example is digital comics on specific sites in a scene, where the story's dialogue leads to an introduction of beauty products that are then directed to a website address. However, if it is said to be too narrow, another example is Ambient Media, which can bring the audience to a series of understandings through the association of forms.

Considering that today's media landscape is expanding because the flow of technological developments drives it, and in the debate in the design world, a new category has emerged with the term Through the Line (TTL) - a media that takes shelter in the digital area through platforms that provide various features. This media is not only able to enter a portion of the top and bottom-line media portions but is increasingly shifting the role of the media (though not totally). This is because of its practical efficiency. This reconstruction of media distribution is used en masse by small entrepreneurs is introducing their entrepreneurship and by big brands such as Coca-Cola, which can actualize a product theme in many countries.

\subsubsection{Visual Concept}

Concepts can offer a variety of ideas that are formed to bring out the values contained in them. The note is that value can grow because of a perspective attached to the intellectual level of an interpreter. Emotions are what make the media and visual concepts valuable. What has become a must in designing media in the context of advertising is how designers can display the quality of empathy, where the emotional content bridges the connectedness of the product with the audience.

In Design Redefinition, [10] describes how important empathetic behavior is in understanding subject variables in design research. According to him, designers who have a high empathy attitude will find it easier to understand a phenomenon because they are accustomed to placing themselves in various situations and other people's positions, building networks through collaboration and collaboration to solve a problem together, and are accustomed to creating value-oriented orientation. Novelty. Because empathy can adapt to changes. This means that with empathy, what has been designed is practical and becomes authentic because it is based on a focused understanding. 
However, so far, we still need to understand some of the possibilities that can be parsed. The primary basis that we can read can be from value as functionality and aesthetic value. However, in a diversity of services and products, we can review many other aspects that can be used as pillars of value, such as historical values, materials and production processes, and theme approaches to establishing a brand in positioning its products in the market. Its function is none other than positioning so that it is embedded in the audience's minds as a place to place an impression that becomes ideal for each class and its needs. This is where we can put these values visually from what is contained in the media. Moreover, we can even display multiple values in a single concept selection.

We can understand a product/service for a function. In the workings of functions that intersect in an empathetic way, this can be through an approach to what is a need, from creating an effect caused by the product. A homemaker can be very concerned about choosing a bleaching detergent for her family, and the approach taken is the image of affection in clothing that uses detergent. The value of a mother's love for her family lies in a pile of clean and fragrant laundry. The value of this function can enter every detail of any need through a hyperbolic emotional approach.

Next is empathy's aesthetic value, which is still very much connected with the value of functionality. Besides aesthetics being part of the function itself in a product, then the value of beauty itself can be read as a secondary item that can sometimes go beyond a basic need. The entrance is through from what is packaged to be an interesting one. This means that we are not just talking about mere function. Beauty can create an interest that is very open to a response that triggers a consumptive culture. If indeed there is a dynamic pressed for an aesthetic value, then the trigger is none other than the media that can give that impression by installing a feature as the identity of the group/environment. For example, Parka Jackets no longer stand only as their initial function as body warmers. However, the jacket model has become a hallmark of a Scooter (Mods) community. I want to highlight a design form with a specific model that enters the identity space, where the empathetic side can read an existential emotional movement in the status of wanting to have and wanting to be recognized as members.

Another alternative is through a specific theme approach. In this way, the positioning of the product can be more focused. We can associate the product in other forms, even at extreme times. These impressions work through deliberately directing products into specific theme categories. These themes bring a sensation to their customers, who are also encouraged through their promotional media. In extreme cases, we find many products/services that usually cannot be penetrated by exposing their form or activity. As in the case of cigarettes or sexual products. As in cigarette products that are suitable if enjoyed in mountainous nature or moments of nature.

Others offer visual concepts, such as in the form of historical studies on how the company defines itself as an experienced product/service in a specialized context. For example, in the example of the herbal medicine, Nyonya Meneer, by placing himself in a stable slogan, "Stand Since 1919". Alternatively, TVC packaging is designed to display historical documentation.

Another feasibility in visual concept in functional and aesthetic values can enter the material space and the production process how a company exploits product ingredients and is strengthened by the production process. This is to establish themselves as a service product/service in a severe category. For example, food products prioritize customer satisfaction through visual exploitation by presenting selected ingredients and hygienic processes. Or also in the example of handmade products, such as leather. How we bring out the quality of craftsmanship is parallel in design definition. Material selection and expertise in measuring prototypes require patience to produce value in problem-solving efforts. If the process can be packaged emotionally, as the advertisement works by taking more value from what is contained in the product, it will be able to enter an intelligence perspective, where the audience can process that value into 'valuable' goods.

Nike sports shoe company has made more unusual ways of association, such as installing a garden chair (with the logo) without a sitting mat. He no longer talks about the quality of the soles, sewing techniques, or highgrade materials. He only 'forces' the audience to enter into the notions that contain it all through the media in the public sphere. As well as encouraging audiences on many other bits of intelligence, which include health values or patterns of exercise habits. Of course, it is obtained through empathy how the design can read the audience's wishes in terms of the value categories it wants to achieve.

The things above are a series of alternative efforts on how the product image is formed in many ways. In order to impress the audience and get as many consumers as possible. We must return it all to the consumers' level of intellectual and purchasing ability. Not all products 
require different associations. However, creativity can still lead to a certain quality by weighing the weight of the market. What is clear, as actors in the design, problem-solving efforts in the context of the advertising industry, the effort is emphasized on the quality of empathy. How do we load the emotional connection of products with consumers?

Beyond that, some things need to be considered more specific than what has been conceived, namely to realize a unified composition, among others, determining what icon we should appear. We can place specific figures as figures designed to be attached to the product. Then, we apply color tones to obtain a matching theme between the background and the object. For example, we can also apply a color scheme to the cinematic framework, such as Analogous, Square, Triadic, Complementary, and Tetradic. Alternatively, maybe simply by using a choice of cold or hot colors. For a series of print media, color coding is essential to consider the production system later, such as determining RGB or CMYK, which is connected to the color code. Another thing that should be part of a composition is the selection of font types in the complexity of the media.

\subsubsection{SWOT Analysis (Media)}

At this point, analysis is considered an essential phase towards media forming, which means that we could measure the media potential that would be designed.

1) Strength. This subpoint can be filled by loading the advantage of the quality of the media to be designed. For example, if the media design is classified as a new form of media or the closeness of the character of a chosen icon to consumers, it could also be a relatively cheap medium to produce.

2) Weakness. The weakness of media has been confirmed that it always be there. This reading could be the function to be overcome later. For example, it requires a particular application or an internet signal, such as licensing difficulties in placing Ambient Media in a public space where you have to remodel existing devices.

3) Opportunities. Opportunity is always connected with expertise in cultivating Strength and Weakness, which takes advantage of it as an opportunity for momentum. We can see media opportunities based on a strategic location. We can also read certain gadgets/ social media phenomena that are happening and popular currently, or even take advantage of the moment when there is a problem in the public eye regarding lousy judgment. That kind of thing can become an opportunity from what we offer through the media.

4) Threats. A common threatening problem in the world of advertising is seeking its continuity. That is the reason why big brands like Adidas and Nike are constantly updating their brands through advertising. The increasingly fierce level of competition requires companies to continue offering new things constantly, and it requires a pattern that continues so that the doctrine is maintained in the minds of consumers. However, that does not mean that the problem is what is considered 'threatening.' Several other factors could stem from technical problems, such as the delivery service by Gofood, which GPS often loses, or the Shopee COD system, which leads to rejection and complains, or perhaps the placement position.

\subsubsection{Pre-Production}

Research and concept-making are the steps of the pre-production process explained above. Other steps might need in some processes, for instance: script formulation, sketch, storyboard, and so on. Other steps are prepared for technical for the next production step, such as team gathering and job description, and other materials and equipment for the production.

\subsubsection{Production}

This is when the media is designed to search the problem solution contextually, medially, or visually. If needed more than one, it would be continually so that the phase would work well and holistically.

\subsubsection{Post-Production}

This section is the stage of the formulation results through a design scheme that works in media distribution and application. In addition, this stage can also lead us to find out the effectiveness of a media (applied) in serving these products/services. There are several ways to find this out, such as; a Nielsen rating, or reading the value of fluctuations in sales status as a form of consumer response, application installation statistics (in some instances; such as Black Pink on Shopee), ratings on applications that assess customer satisfaction, community analysis through posts on social media, 
scholar analysis, or even more profound as a symptom of assimilation into the culture of society. In the last possibility, we can find a successful slogan published through promotional media that came through word of mouth - "played, licked, kept dipped."

These things become an equity value that is not only to understand the success of the media but can be a complex evaluation area at the company stage and a stimulus for designing media at other stages. This way of reading is needed by industries that are required to always move in defense of companies/products/services amid market competition. This case is very relative. We can start from only certain parts.

\section{RESULTS AND DISCUSSION}

This point is an extension that can be used by students who are struggling with Final Projects (especially in product campaigns). By representing what is designed and its achievement. The content is to present a descriptive analysis discourse that connects the problem, the luxury of theory, field data, design concepts, and the media itself. Media analysis and visual elements are read in detail, such as the size of the letters in a media by considering the theme, type, size, viewing distance. Another essential part of a report chapter is how its role is crucial in a logical explanation.

\section{CONCLUSION}

In the context of advertising in Visual Communication Design, what is needed is not only creative ideas but also a process of reviewing how the idea can stand as text in context. This means that what is displayed is based on mature research by reviewing elementary aspects to form concept maturity. Moreover, as sought in this design scheme, an alternative to the choice of methods, a thorough exploration of materials can be used as a choice of concept and media design, especially in anticipation of a rejection of the concept. The scheme offered would be presented in elemental form. In the future, it would need more comprehensive adjustments in every application because every advertising case study needs more improvements and adjustments in every way visual media appears.

\section{REFERENCES}

[1] F. Adiloglu, "Visual communication: Design studio education through working the process," Procedia - Soc. Behav. Sci., vol. 28, pp. 982-991, 2011, doi: 10.1016/j.sbspro.2011.11.182.

[2] B. U. Dur, "Data Visualization and Infographics In Visual Communication Design Education at The Age of Information," J. Arts Humanit., vol. 3, no. 5, pp. 39-50, 2014, doi: 10.18533/journal.v3i5.460.

[3] R. Veum, "What is a promotion?," Ind. Labor Relations Rev., vol. 52, no. 4, pp. 581-601, 1999.

[4] C. Gurău, "Integrated online marketing communication: Implementation and management," J. Commun. Manag., vol. 12, no. 2, pp. 169-184, 2008, DOI: $10.1108 / 13632540810881974$.

[5] S. Zubaidah, N. M. Fuad, S. Mahanal, and E. Suarsini, "Improving creative thinking skills of students through Differentiated Science Inquiry integrated with a mind map," $J$. Turkish Sci. Educ., vol. 14, no. 4, pp. 77-91, 2017, doi: 10.12973/tused.10214a.

[6] A. Cropley, "In Praise of Convergent Thinking," Creat. Res. J., vol. 18, no. 3, pp. 391-404, 2006, doi: 10.2118/120203-stu.

[7] M. A. Runco and S. Acar, "Divergent Thinking as an Indicator of Creative Potential," Creat. Res. J., vol. 24, no. 1, pp. 66-75, 2012, doi: 10.1080/10400419.2012.652929.

[8] S. Chotipanich, "Positioning facility management," Facilities, vol. 22, pp. 364-372, 2004, doi: 10.1108/02632770410563086.

[9] P. L. Plaisance, "The Concept of Media Accountability Reconsidered," J. Mass Media Ethics, vol. 15, no. 4, pp. 257-268, 2000, doi: 10.1207/s15327728jmme1504_5.

[10] D. Oswald, "Towards a redefinition of product design and product design education," DS 62 Proc. E PDE 2010, 12th Int. Conf. Eng. Prod. Des. Educ. - When Des. Educ. Des. Res. Meet, no. September, pp. 36-41, 2010. 